\title{
Educação Financeira Crítica: Novos Desafios na Formação Continuada de Professores
}

\author{
Ana Paula Rohrbek Chiarello ${ }^{1}$ \\ Mestre em Educação pela Universidade Comunitária da Região de Chapecó (Unochapecó), \\ anapaula.rc@unochapeco.edu.br
}

\section{Luci dos Santos Bernardi}

Docente pesquisadora do Programa de Pós-Graduação stricto sensu em Educação da Universidade Comunitária da Região de Chapecó (Unochapecó).

lucib@unochapeco.edu.br

\section{Resumo}

O presente artigo discute a compreensão dos professores sobre possibilidades de promover uma Educação Financeira Crítica em sua prática de ensino. A pesquisa é de natureza qualitativa, inspirada na pesquisa-ação participante, realizada através de um processo de formação continuada com professores da educação infantil e anos iniciais, à luz dos pressupostos da Educação Matemática Crítica. O resultado é discutido em quatro dimensões: i) da proposição de atividades investigativas; ii) das dificuldades apresentadas pelos professores para estruturar um ambiente de aprendizagem; iii) do sentido atribuído ao papel sociopolítico da Educação Financeira; iv) das mudanças na ação pedagógica dos professores.

Palavras-chave: Educação Financeira. Educação Matemática Crítica. Formação continuada de professores.

\section{Critical Financial Education: New Challenges in Continuing Education Teachers}

\begin{abstract}
This article discusses the understanding of teachers on ways of promoting a Financial Education Critical in their teaching practice. The research is qualitative in nature, inspired by the participant action research. The research is qualitative in nature, inspired by the participant action research, carried out through a process of continuing education with teachers of early childhood education and early years, according the theory of Critical Mathematics Education. The result is discussed in four areas: i) the proposal of investigative activities; ii) the difficulties faced by teachers to structure a learning environment; iii) the meaning attributed to the socio-political role of financial education; iv) the changes in the pedagogical action of teachers.
\end{abstract}

Keywords: Financial Education. Critical Mathematics Education. Continuing education of teachers.

\footnotetext{
${ }^{1}$ Bolsista CAPES/Prosup
} 


\section{Introdução}

A proposta de trabalho ora apresentada tem como tema a Educação Financeira - (EF) na prática escolar da Educação Básica (infantil e anos iniciais) e a Formação Continuada do Professor, importantes regiões de inquérito do debate contemporâneo na Educação. O texto traz um recorte de uma pesquisa desenvolvida ${ }^{2}$ com objetivo de identificar, em um processo de formação continuada, como os professores compreendem a possibilidade de promover uma Educação Financeira Crítica em sua prática de ensino.

Apesar de sabermos e expressarmos a importância da EF na sociedade, para a educação formal este é um tema ainda novo, despontando no contexto acadêmico a análise sobre sua inserção na escola e o pensamento dos educadores sobre o tema. Atualmente, estão sendo realizados testes pilotos em algumas escolas da Educação Básica - tendo, inclusive, a EF como disciplina - desde os anos iniciais. Assim, obstáculos e inquietações vão surgindo, na medida em que os estudos avançam de forma que emergem novos desafios para o desenvolvimento dos processos, entre os quais se torna importante evidenciar os processos escolares e gestão, os paradigmas educacionais e a formação dos professores.

Compreender esses três desafios e compor um cenário inicial tomou uma dimensão significativa durante a dissertação: queríamos explicitar "de que lugar estamos falando" quando falamos em EF e Formação Continuada de Professores, e essa tecitura, que descrevemos a seguir, foi fundamental para as definições de toda a caminhada da pesquisa.

O primeiro desafio nos fez pensar na concretude da EF no processo escolar formal brasileiro e sua gestão. A implantação da EF como disciplina curricular ainda não é tida como obrigatória pelo MEC (Ministério da Educação), uma vez que considera esses conceitos como um dos temas transversais ao currículo escolar, embora já exista uma tramitação no Senado Federal para tornar o tema obrigatório na grade curricular. Essas informações podem ser encontradas no PLS (Projeto de Lei do Senado) 171/2009, em seu “Art.26: $\S 7^{\circ}$, no qual o tema EF integra o currículo da disciplina Matemática”. O projeto de Lei n 3401 , de 2004, apresentou como proposta inicial a criação da disciplina EF, no entanto, houve um substitutivo desse projeto orientando que seja incluída no conteúdo da matemática de forma transversal, interno ao currículo, conforme intitulado pelo MEC, promovendo um diálogo articulador entre as áreas do conhecimento como meio ambiente, trabalho e consumo, com os quais precisa dialogar regida por valores e competências.

Precisamos considerar que recebemos cotidianamente muitas informações, pois o mundo passa por rápidas transformações em todos os seus segmentos, sejam eles políticos, sociais e econômicos. Vivemos imersos em uma sociedade de propagandas que, em seu sentido mais amplo, buscam "facilitar" a vida e as escolhas das pessoas. Mas qual é o verdadeiro entendimento sobre a variedade dos produtos financeiros? Quem consome, procura entender ou estudar sobre suas aquisições? Como o jovem compreende e se posiciona diante das situações de consumo? Essas inquietações explicitam a importância que a inserção da EF na escola assume, e ainda, que conceitos, valores e referências dão sustentação a esse debate no âmbito escolar. Enfim, quais são os paradigmas educacionais, é o segundo desafio que nos empenhamos a examinar.

2 Dissertação de Mestrado defendida por Chiarello (2014) no Programa de Pós-graduação Stricto Sensu em Educacão da Unochapecó, sob orientação de Luci dos Santos Bernardi. 
Pensando os caminhos da EF na escola, destacamos como terceiro desafio a formação do professor, em especial a continuada, debate central deste artigo, que tem por objetivo identificar, como os professores compreendem a possibilidade de promover uma Educação Financeira Crítica em sua prática de ensino.

\section{A Educação Financeira como Projeto Coletivo: uma perspectiva crítica}

Pensar a EF como um projeto coletivo nos remete ao conceito de projeto com o ponto de partida etimológico. De acordo com Machado (2000, p. 2), “A palavra projeto deriva do latim projectus, particípio passado de projícere, significando algo como um jato lançado para frente.” Ainda para o autor, duas famílias de proximidade podem contribuir para a ideia de projeto, problema e programa; no que se refere à raiz, partilhando com palavra como sujeito, objeto e trajeto.

Skovsmose e Penteado (2008) nos indicam a ideia de projeto como uma tarefa coletiva em forma de rede, onde cada indivíduo necessariamente precisa de outras pessoas e diferentes recursos para executar seus planos e atingir suas metas. Para os autores:

Trabalhar com projetos significa se movimentar numa rede cujos nós são pessoas, objetos, instituições, entre outros. O acesso a esses nós não ocorre através de um caminho único. É possível adotar percursos diferentes. O movimento altera o contexto e o resultado. Numa rede não existe um centro e, pela sua mobilidade, todos os nós podem constituir-se no centro. O ritmo, a forma, as opções e as necessidades emergirão da situação e serão locais, datados e transitórios. (SKOVSMOSE; PENTEADO, 2008, p. 4-5).

Machado (2000) relata a concepção de cidadania como a construção de instrumentos legítimos de articulação entre projetos individuais e projetos coletivos: "tal articulação possibilitará aos indivíduos, em suas ações ordinárias, em casa, no trabalho, ou onde quer que se encontrem, a participação ativa no tecido social, assumindo responsabilidades relativamente aos interesses e ao destino de toda a coletividade". (MACHADO, 2000, p. 43)

Essa ideia de rede nos desafia a pensar uma EF que tenha preocupações com a solidariedade e com noções de cidadania, preocupações essas que têm a ver com: a função do dinheiro; a percepção dos desejos versus necessidades; a noção do caro versus barato; o consumismo, entre outros.

Acreditamos que essas preocupações contribuem de forma significativa para que a EF oportunize às crianças e aos jovens avistarem novos horizontes na construção de seus projetos de vida, mais conscientes de que todos os sujeitos precisam tomar para si as dores do mundo; de que cada ação, de cada um de nós, interfere sempre nos resultados de um coletivo e não podemos nos furtar de refletir sobre isso. Ainda, acreditamos que a escola seja o local onde essas possibilidades podem se concretizar, quando estudantes e professores desejarem que esse novo horizonte não seja uma utopia, e sim, um projeto com significado e realizado de forma coletiva e investigativa, tencionando as diversas concepções da EF na/pela sociedade, pensando nas relações de poder estabelecidas, na justiça social, na igualdade, nas incertezas e na globalização. Esse tencionamento ocorre no campo da Educação Matemática Crítica.

O termo Educação Matemática Crítica (EMC) começou a surgir através de movimentos na década de 1980, movimentos esses que se preocuparam fundamentalmente com aspectos políticos da educação matemática, ou seja, trazem para o centro do debate questões relacionadas ao poder. De acordo com Alro e 
Skovsmose (2010), o foco problemático da EMC não é "científico" ou "didático" mas sim político, trazendo muitas questões de democracia e justiça social para debate. Para Skovsmose (2001), a matemática torna-se parte da linguagem do poder, amparada pela ideologia da certeza. ${ }^{3} \mathrm{O}$ autor levanta a possibilidade e necessidade de se construir uma pedagogia que combata a opressão na sociedade, já que essa visão de matemática corrobora a noção de que a matemática é livre da influência humana. Para Skovsmose (2001) a base ideológica pode ser resumida da seguinte forma: "matemática é relevante e confiável, porque pode ser aplicada a todos os tipos de problemas reais. A aplicação da matemática não tem limite, já que é sempre possível matematizar um problema". (SKOVSMOSE, 2001, p. 131)

De fato, precisamos considerar que a interpretação matemática aqui citada é uma (dentre as tantas possíveis) alternativa. No contexto escolar, especificamente nas aulas de matemática, busca-se minimizar o impacto da ideologia da certeza, buscando na ideologia da incerteza razões mais lógicas possibilitando práticas pedagógicas nas perspectivas de EMC.

Algumas reflexões e alguns diálogos são apresentados por Araújo (2007), contextualizando que a EMC é a matemática em ação que deve ser identificada, analisada e refletida criticamente em todo e cada caso. Nos anos iniciais, as crianças apresentam maior desenvoltura em relação à Educação Matemática, desenvoltura essa que vai desaparecendo com o decorrer dos anos. Segundo Araújo (2007),

$\mathrm{Na}$ educação matemática escolar observa-se a presença da ideologia da certeza em problemas matemáticos com uma única resposta correta; nas posturas por vezes arbitrárias do professor, quando não proporciona aos alunos momentos de reflexão e questionamentos durante as aulas; na definição dos currículos das séries, nas atitudes dos próprios alunos, que, em algumas situações, demonstram insegurança perante problemas com soluções mais abertas. (ARAÚJO, 2007, p. 40)

Diante dessa situação, surgem alguns questionamentos que buscamos esclarecer nessa pesquisa: Quais as dificuldades apresentadas pelos professores para estruturar o ambiente de aprendizagem diante da proposta da Educação Matemática Crítica? Qual o sentido que os professores atribuem ao papel sociopolítico da matemática que está sendo ensinada? Que atividades matemáticas os professores planejam e desenvolvem em suas aulas de forma crítica?

A EMC surge para dar suporte a esses pensamentos. Segundo Skovsmose (2007), surge estando consciente da situação dos estudantes, de que possibilidades para o futuro uma sociedade pode promover aos estudantes e também para possibilitar reflexões sobre a presença da matemática na sociedade, seja em benfeitorias ou problemas sociais.

De acordo com Skovsmose (2007), a EMC tem, como foco, o meio social e político, buscando uma prática democrática no processo ensino aprendizagem, por meio do qual o aluno é convidado a refletir sobre a matemática vivenciada em seu contexto, em uma perspectiva crítica.

3 Na educação matemática escolar, observa-se a presença da ideologia da certeza em problemas matemáticos com uma única resposta correta; na postura por vezes arbitrária do professor, quando não proporciona aos alunos momentos de reflexão e questionamentos durante as aulas; na definição dos currículos das séries, nas atitudes dos próprios alunos que, em algumas situações, demonstram insegurança perante problemas com soluções mais abertas (ARAÚJO, 2007, p. 40). 
Ancorados em Skovsmose (2008), percebemos que o trabalho com projetos tem sido uma resposta emblemática aos desafios educacionais lançados pela EMC. Então buscamos aproximações com o espaço da escola, caracterizado como ambiente para investigação, para isso novos desafios precisam ser lançados. Para Skovsmose (2008, p.13), "não se pode esperar por qualquer tipo de conforto, quando se entra em um cenário para investigação". Com esse olhar, propomo-nos a entender a profissionalização do professor com um caráter crítico e reflexivo. Assim, empreender um estudo sobre a formação continuada do professor como atividades coletivas e indissociáveis do exercício da profissão, nos possibilitou pensar "Os Caminhos da EF na Escola: E agora professor?"”

\section{Os Caminhos da Educação Financeira na Escola: e agora professor?}

Ao voltarmos nossos olhares para o fazer na escola, questionamo-nos sobre as tensões que ali se estabelecem, considerando os diferentes elementos que constituem o cotidiano escolar. Como o professor pode trabalhar com os estudantes o conhecimento sobre como gerar recursos, consumir e economizar? Como perceber que são as escolhas e atitudes para esse trabalho que oportunizam aos estudantes a construção de um campo reflexivo decisivo para desenvolver sua postura crítica de forma ética, consciente e responsável? Esse é o grande desafio!

Propomo-nos a iniciar este desafio pelo espaço escolar, pensando em um possível movimento dos professores na elaboração de um projeto na perspectiva da Educação Financeira Crítica.

A partir do contexto apresentado, discutimos acerca da formação continuada do professor na perspectiva de um profissional reflexivo, ampliamos esse debate considerando os processos formativos e suas relações com atividades coletivas e indissociáveis do exercício da profissão.

A formação continuada do professor é importante campo reflexivo para educadores e pesquisadores. Ela representa um enfrentamento a desafios cotidianamente colocados à comunidade educacional em busca de melhor qualificação e profissionalização do professor.

Ao longo do tempo, vários termos foram utilizados como referência para o processo de formação em serviço, tais como: capacitação, aperfeiçoamento, treinamento, reciclagem, formação permanente, formação continuada, educação contínua, desenvolvimento profissional ou profissionalização. As terminologias presentes na literatura podem ser associadas às concepções de cada época em que esses processos foram ancorados, sendo desde simples treinamento para habilitar os professores em determinadas técnicas até uma concepção de formação permanente, na qual o docente está em constante interação e discussão com os novos conhecimentos e metodologias para enfrentar as demandas do cotidiano escolar.

Entendemos que a formação continuada precisa ser compreendida como um processo permanente, integrado ao cotidiano da sala de aula, que tenha como objetivo primordial formar o cidadão crítico com condições de se posicionar de forma consistente diante das problemáticas sociais e que seja capaz de enfrentar o desconhecido e de criar o novo. De acordo com André (2010), a formação docente tem que ser pensada como um aprendizado profissional ao longo da vida, o que implica envolvimento dos professores 
em processos intencionais e planejados, que possibilitem mudanças em direção a uma prática reflexiva em sala de aula.

Algumas alternativas que podem contribuir para melhorar a formação dos professores são apresentadas por Vaillant (2001). Entre elas, podemos destacar a articulação da formação em centros educativos, a reestruturação de programas de formação para fortalecer os vínculos entre a teoria e a prática, a reforma das condições de trabalho nas escolas, estabelecendo uma prática profissional comprometida com os educadores e o conhecimento.

Assim, a formação continuada deve proporcionar ao professor práticas que the possibilitem uma aprendizagem que permita um maior desempenho em suas atitudes pedagógicas, de forma permanente. Entretanto, a aprendizagem só será significativa, conforme proposta de Silva (2005), quando o processo formativo propuser mudanças, tendo como base as trocas de saberes entre professores, projetos articulados de reflexão conjunta, construção de conhecimentos pelo sujeito.

Um de nossos propósitos é propor um olhar sobre o ensino da matemática, resgatando a importância de professores reflexivos, capazes de agir, possibilitando realizar uma Educação Financeira Crítica. Consideramos que cabe aos professores, compreenderem a importância de desenvolverem suas aulas de forma que oportunizem aos alunos a mobilização de diferentes habilidades, como ter autonomia, saber pensar, criar, aprender a aprender, de modo que possam continuar o aprimoramento de suas ideias, ações e reflexões.

\section{Possibilidades construídas pelos professores}

A pesquisa descrita neste artigo foi desenvolvida em uma Escola Municipal Nucleada localizada em cidade do oeste catarinense, com professores que atuam na educação de anos iniciais e educação infantil. O trabalho foi realizado por meio de pesquisa de campo, através de um processo de formação continuada. O grupo contou com 22 participantes e a mediação se deu em encontros de outubro de 2013 a maio de 2014.

O tempo de formação foi dedicado aos encontros do grupo de professores para estudos, debates, avaliação das atividades desenvolvidas, elaboração de novas atividades; e o tempo de escola para desenvolvimento das atividades dos professores com os estudantes. Os dois momentos ocorreram de forma concomitante.

A proposta de trabalho foi organizada em três eixos: "Conhecendo o dinheiro", "Usando o dinheiro" e "Gerando o dinheiro". A atividade apresentou aporte teórico nos pressupostos da EMC.

Trabalhamos na perspectiva de categorias emergentes. Durante o processo de coleta de dados, não possuíamos categorias pré-estabelecidas à análise. O material de campo constitui-se em textos transcritos, organizados por encontros a partir da fala e materiais produzidos pelos professores.

Com esse intuito, a pesquisa foi desenvolvida em duas etapas: a primeira, fase exploratória, teve por objetivo sensibilizar os professores acerca da necessidade e das possibilidades de trabalhar essa temática 
numa perspectiva crítica e reflexiva com os educandos, o que permitiu discutir o papel sociopolítico da matemática e as relações de poder envolvidas.

Nesse contexto, muitas inquietações se fazem presentes quando pensamos no espaço que a Educação Financeira ocupa e/ou pode ocupar na escola atualmente. Inquietações que perpassam por questões como os conteúdos propostos pela escola e as dificuldades apresentadas pelos professores em organizar essa proposta, e se ampliam para discutir a formação do professor e sua mobilização para mudanças na ação pedagógica, na perspectiva da EMC.

$\mathrm{Na}$ segunda etapa, foi realizada a formação continuada com os professores, considerando a necessidade de uma ação inovadora relacionando a matemática com diferentes realidades, sejam elas sociais, culturais ou econômicas, buscamos em Skovsmose (2001) a possibilidade e necessidade de se construir uma pedagogia que "combata" a opressão na sociedade, já que essa visão de matemática corrobora a noção de que a matemática é livre da influência humana e superior aos seres humanos.

A partir do trabalho realizado com os professores, tínhamos a expectativa que eles propusessem aos alunos atividades investigativas com referência na realidade social e na matemática, relacionando a EF. A trajetória de formação, entretanto, foi marcada por muitas incertezas, causadas ao propor um ambiente de aprendizagem diferente, podemos observar nas considerações que seguem:

\section{(i) Da proposição de atividades investigativas}

Nas atividades propostas ao $5^{\circ}$ ano $^{4}$, os professores partiram de uma sequência explicativa sobre gerar e gastar dinheiro na família, em seguida utilizaram a caixa de torneiras ${ }^{5}$ seguindo um roteiro de perguntas durante a atividade. $\mathrm{O}$ valor a ser gasto foi estipulado a partir da pesquisa realizada pelos alunos com as famílias sobre os gastos mais importantes, mais caros e supérfluos. Em sala de aula, reafirmaram esse contexto, utilizando-se da caixa de torneiras. Nessa direção P2 comenta:

Quando utilizamos a caixa de torneiras, seguimos um roteiro de perguntas, possibilitando os grupos elaborarem explicação sobre como gastam o dinheiro, por exemplo, os alunos precisavam descrever quanto gastaram com água, luz, alimentação, roupas, compras, transporte. $O$ valor a ser gasto foi estipulado a partir da pesquisa sobre como as famílias geram dinheiro e partindo de um valor médio de renda das familias. Formularam-se três grupos e cada grupo elencou seus gastos mais importantes, mais caros, necessários e após a elaboração da apresentação foi feita a apresentação para a turma. $\mathrm{P} 2^{6}$

\footnotetext{
$4 \quad$ As atividades foram desenvolvidas com quatro grupos de trabalho: educação infantil (A), $1^{\circ}$ ano e $2^{\circ}$ ano (B), $3^{\circ}$ ano e $4^{\circ}$ ano (C) e $5^{\circ}$ ano (D). Neste caso, faremos uma amostra a partir do grupo D.

5 Recurso didático pedagógico apresentado na figura 1, fornecido pela pesquisadora, com objetivo de possibilitar aos alunos um entendimento do planejamento financeiro, com torneiras para observar a entrada e saída de recursos.

${ }^{6}$ Consideramos importante preservar os participantes, chamando-os de P1, P2, P3 e assim sucessivamente.
} 
Figura 1 - Atividade $5^{\circ}$ Ano
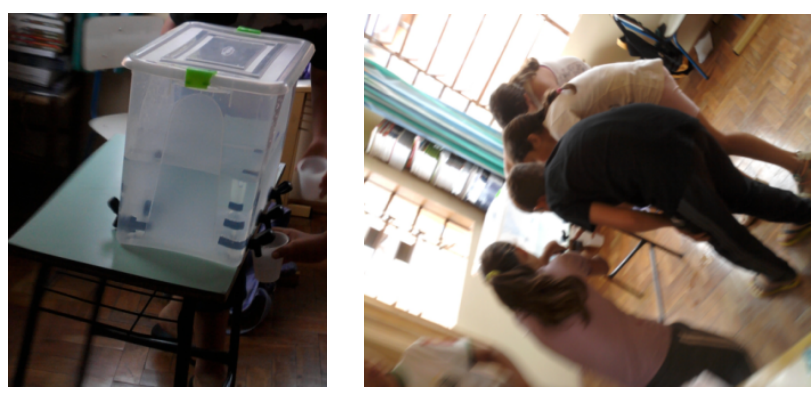

Fonte: Chiarello (2014).

Outra atividade realizada pelo grupo de professores com a turma do $5^{\circ}$ ano foi uma visita a um supermercado da cidade, conforme relato a seguir:

A turma foi dividida em três grupos, cada grupo recebeu $5^{\circ}$ reais e teriam que comprar lanches para um piquenique na sala. Os lanches que comprados seriam compartilhados na sala e assim foi feito. Um grupo escolheu comprar um item de bebida e outro de comida para todos e os outros dois grupos compraram vários itens de lanche. Durante a compra teriam que fazer cálculos para saber se o dinheiro seria suficiente para pagar a compra, todos os grupos realizaram a atividade sem muitas dificuldades, mas conversaram bastante entre eles para decidir o que e como fazer. (P 2).

Segundo os professores, a atividade foi um processo de construção de forma dinâmica e diferenciada, possibilitando uma construção conduzida e, ao mesmo tempo, uma produção do grupo com autonomia em suas decisões. Conforme Leite (1996 apud BITENCOURT, 2010), apresentar as novas aprendizagens é um momento de reflexão sobre o Projeto aplicado, bem como um resgate de conceitos e valores construídos, informações adquiridas, questões esclarecedoras e também novos problemas que precisam ser resolvidos em outros Projetos ou em outros momentos em sala de aula.

Percebemos, aqui, certa dicotomia entre a primeira e a segunda atividade apresentadas ao $5^{\circ}$ ano. No primeiro momento, os professores utilizam de recursos didáticos e pesquisa, porém seguiram um roteiro de perguntas preestabelecidas, ou seja, estabelecendo um 'caminho' para este trabalho, "quebrando" o ambiente de aprendizagem proposto aos alunos. No segundo momento, preparam uma atividade "dinâmica e diferenciada", porém, o consumo esteve muito presente nela.

Assim, propomos um processo de formação teórico-prática que permitiu ao docente lidar com as diversidades culturais, buscando, não somente os meios pedagógicos-didáticos para organizar o ensino da EF, mas também oferecer condições para o desenvolvimento de conceitos que favoreçam uma apropriação crítica desse conhecimento. Desse modo, a formação continuada do professor, pensando no desenvolvimento de Projetos, assegura a inserção da EF numa perspectiva crítica.

ii) Das dificuldades apresentadas pelos professores para estruturar um ambiente de aprendizagem 
Durante a pesquisa, foi possível observar algumas dificuldades apresentadas pelos professores para estruturar o ambiente de aprendizagem. No decorrer da proposta, uma das dificuldades mais presentes emergiu dos professores de educação infantil, que trabalharam somente com a abordagem de "conhecer o dinheiro", devido à faixa etária dos alunos ser de um a 5 anos, considerando que as crianças ainda não conseguem entender e desenvolver as habilidades de "usar o dinheiro" e "gerar o dinheiro". Assim,

É difícil criar um cenário para investigação vindo de crianças que ainda não tem uma reflexão formada, para eles tudo é novo. O que conseguimos trabalhar foi contar a história do dinheiro, alguns até prestarão atenção, enquanto para outros aquele assunto não tinha interesse. Pois, a realidade de cada aluno é diferente, alguns já manejam e até entendem que os pais precisam trabalhar para ganhar, enquanto outros nem conheciam o dinheiro. P 8 .

Percebemos nessa fala certo receio quanto às mudanças a serem realizadas. Para o grupo de professores, trabalhar nesta perspectiva demanda "muito tempo". Para a análise, eles consideraram o trabalho do qual já participaram com tema gerador da perspectiva Freiriana. De acordo com os professores, "tínhamos que responder aos alunos suas dúvidas demandando mais tempo em nossos planejamentos, pois as perguntas tinham que partir deles” (P 14).

Observamos nas falas do grupo de professores a preocupação com os conteúdos a cumprir, algo típico do paradigma do exercício, oferecendo dessa forma uma fundamentação baseada na "tradição", ou seja, baseada na ideologia da certeza.

No entanto, a perspectiva do grupo foi de adentrar para o estudo da EF, buscando espaços para ação e reflexão. Porém, muitas vezes os professores se mostraram inseguros, no sentido que precisam estar preparados para tudo o que vão enfrentar com os alunos. A postura deles demonstrava a necessidade de segurança e previsibilidade, todo o controle é seu, situação que nomeamos de Zona de Conforto. Deslocar sua prática para um espaço dialógico de situações imprevisíveis, de questões e problemáticas que emergem dos estudantes, para os quais podem não ter respostas, é um desafio, é um movimento para uma zona de risco.

\section{iii) O sentido atribuído ao papel sociopolítico da EF}

Refletir sobre o sentido que os professores atribuem ao papel sociopolítico da EF leva-nos a repensar suas experiências, bem como suas relações com a EMC.

Iniciamos este enfoque baseados no seguinte recorte, da fala do professor P12: "despertou o interesse pelo dinheiro. Tiveram interesse e curiosidade, mas pelo fato de ser uma vivência diferente, com atividade diferente realizada na sala de aula."

Percebemos um interesse dos alunos em compreender a EF, assimilando a fala da professora P4 "a felicidade deles era explicita, estar comprando, fazendo o troco, pegando os 
produtos era fantástica”. Perguntamos, então: Será que a forma como foi encaminhada essa atividade possibilitou aos alunos uma reflexão crítica?

Percebemos um convite ao consumismo, ou seja, faltou um incentivo para o desejo de um controle financeiro, possibilitando aos alunos a tomada de decisão de forma reflexiva, ancorada não só nos desejos, mas também nas necessidades, levando em consideração as relações que podem se constituir em uma sociedade globalizada, as quais, na concepção de Bauman (1999), nada é para durar. Nesse contexto, precisamos atentar as crianças para que estejam em alerta, pois estão a todo momento expostos a novas tentações. Permitindo-nos reconhecer a finitude da educação, do conhecimento.

Buscando atribuir um sentido sociopolítico ao trabalho, uma das atividades esteve proposta a compreender a relação entre salário (valor recebido mensalmente pelo trabalhador) e consumo. Para isso, os professores utilizaram como exemplo uma árvore. Cada aluno fez sua árvore. A atividade foi proposta da seguinte forma: as raízes (que ajudam a alimentar a árvore) representam o salário mínimo e rendimento mensal; os galhos (que necessitam de água e sais minerais enviados pelas raízes) representam as necessidades básicas do trabalhador.

Percebemos que os professores conseguiram estabelecer uma relação complexa, conforme proposto por Morin (2001), de que não se pode isolar uns objetos dos outros, ou seja, salário está relacionado a dinheiro, dinheiro a trabalho. Percebemos na atividade uma relação com o capitalismo, consumismo, tencionando relações sociais, salários, classes sociais e desigualdades.

Para os professores, houve um aprendizado reflexivo por parte dos alunos, afastando a presença da ideologia da certeza tão presente no ensino da matemática. Percebemos, mesmo diante da dificuldade em estabelecer significado para algumas situações, que a EF traz muitas inquietações e curiosidades que mobilizam aos alunos entender as dimensões que os cercam, sejam elas políticas, econômicas ou culturais.

Retratamos essa abordagem em três momentos. No primeiro, observou-se o que os professores consideram como novas aprendizagens; no segundo, foram observados os novos conhecimentos apresentados pelos alunos; e no terceiro momento, a repercussão do projeto na escola.

Percebemos, na conclusão do percurso de formação, uma nova abordagem dos professores sobre uma temática desconhecida por eles no início da formação continuada, demonstrando que estão mobilizados para novas atividades relacionadas à EF.

No entanto, torna-se plausível dizer que muitas das atividades realizadas pelos professores ficaram somente na agilidade matemática, necessitando que se aproximem cada vez mais de cenários para investigação. Dessa forma, ampliando não só o sentido sociopolítico diante de uma 
sociedade de consumo que muitas vezes consegue distorcer o sentido das coisas, quando não se tem instrumentos para o entendimento do papel sociopolítico da matemática em uma perspectiva crítica na sociedade.

\section{iv) Das mudanças na ação pedagógica dos professores}

A construção de um "Projeto" foi uma opção dos professores, uma vez que a escola já trabalha com essa perspectiva. No entanto, o que permeia nossa discussão é a forma como os professores concebem um Projeto, a perspectiva em que propõem o trabalho e, por fim, em que medida o processo de formação provocou mudanças nas concepções dos professores.

Iniciamos o Projeto, já com o tema proposto EF, tendo algumas características importantes em seu planejamento. Freire (1996) apresenta da seguinte forma a inserção do tema gerador na escola: investigação - momento em que o educador fará um levantamento de situações relevantes para os educandos a fim de se direcionar os temas de estudo. Segundo o autor, esse momento é muito importante, pois, na pesquisa do universo temático que envolve as relações homem-mundo, é preciso ter a consciência da necessidade de uma formação crítica que promova a releitura da situação em estudo. Nas palavras de Freire (1996, p. 56), "investigar o 'tema gerador' é investigar o pensar dos homens referidos à realidade, é investigar seu atuar sobre a realidade, que é sua práxis". O segundo momento da implementação do tema gerador na escola é o de tematização: o tema é apresentado ao grupo ainda com a leitura realizada pelos educandos (codificada). Ao passo que se aprofunda o debate (descodificação) os alunos são levados a perceber que chegaram a um limite (situação-limite) e que há mais a se desvendar sobre o assunto. já o momento de problematização constitui-se pelo diálogo permanente entre a teoria e a prática, pois se reconhece que a primeira trará subsídios para uma melhor compreensão da realidade (práxis pedagógica).

Nesse sentido, os professores iniciaram com a busca por situações problemas relacionadas às suas necessidades (professores e escola), preocupando-se com outros projetos já em andamento, bem como com o tempo que se apresentava cada dia mais curto. O que difere dos projetos já realizados para este, são os questionamentos apresentados pelos alunos como uma prioridade, os quais muitas vezes passariam até despercebidos com o uso de outras estratégias.

Os professores destacam que precisam ter "ênfase ao assunto", ou seja, estar preparados bibliograficamente com o assunto para dessa forma conseguir responder a todas as perguntas dos alunos. É nesse sentido que os professores precisam de certo desapego, no que diz respeito às dúvidas apresentadas aos alunos, pois ao propor um ensino investigativo muitas perguntas vão aparecer e o propósito é bem este: possibilitar aos alunos oportunidade de investigá-las. Sobre a pesquisa bibliográfica, até então não realizada na escola, os professores destacam: 
A partir da leitura de texto, artigos, sobre o tema central (Educação Financeira), porém, cada professor desenvolveu suas atividades a partir de um pré-diagnóstico e para a surpresa no decorrer das atividades foram surgindo muitas dúvidas, nos possibilitando aplicar novos Projetos sobre esse tema".P2

"Fui disponibilizado ao grupo diversos artigos para leituras e discussão para a escolha e adaptação conforme a realidade de cada grupo. $\mathrm{P} 8$

Diante dessa abordagem, podemos perceber quais são as expectativas dos professores ${ }^{\mathrm{a}}$ Além de trabalharem com Projetos, buscam aprender novas metodologias. Um ponto importante para nossa pesquisa foi o fato de percebermos que eles já trabalham pensando a realidade social dos alunos, buscando os conhecimentos prévios para então inserir o projeto. Esse interesse mostra a percepção dos professores por novas possibilidades, com desafio lançado para outros projetos, buscando entender outras realidades.

Em relação ao grupo de professores, percebe-se um grande avanço em relação aos projetos, os quais dependiam da proposta curricular e da necessidade da escola. Agora passam a ter um outro enfoque, relacionado às necessidades dos alunos, dificuldades das famílias, propostas de natureza investigativa, possibilitando cada vez mais novos ambientes de aprendizagem em sala de aula.

\section{Algumas Considerações}

Iniciamos esta pesquisa com o propósito de conhecer novos caminhos, instigada por muitas incertezas. Convidamos o leitor para acompanhar nossa caminhada, estabelecendo um diálogo com alguns autores e apresentando o caminho desta trajetória, caminho de muitas idas e vindas, espaços de ações e reflexões.

Com atenção voltada para a EFC, foi necessário entendermos que estamos cotidianamente mobilizados por desejos e necessidade ancorados em um consumismo desenfreado, que está em constante tensão com nossos valores e com nosso orçamento. Precisamos ter determinação, pois são essas escolhas que definem o destino financeiro de cada um de nós, podendo alcançar ou não uma condição de equilíbrio financeiro, almejada por muitos na sociedade atual. Desencadeando esta proposta como um desafio e ao mesmo tempo considerando-a indispensável, propomos ao grupo de sujeitos/professores envolvidos um projeto coletivo, com tencionamento na Educação Financeira Crítica.

Referimo-nos aos caminhos da EF na escola, quando se pretende desafiar os professores por meio de uma formação continuada na perspectiva de um profissional crítico e reflexivo, oportunizando aos alunos diferentes habilidades. Esse contexto nos possibilitou entender alguns movimentos dos professores ao saírem de sua "zona de conforto" para uma compreensão reflexiva em uma "zona de risco", possibilitando novos olhares sobre um cenário de investigação, abrindo espaços para ação e reflexão de forma dialógica.

Revisitar nossas práticas torna-se necessário, no sentido de reorganizar nosso pensamento, pois a reorganização pode potencializar muitas mudanças, em particular, a forma como o significado é produzido. Compreendemos de forma mais efetiva que as rupturas não são imediatas, elas precisam de um processo continuado, que nos aproxime cada vez mais de uma ação transformadora. E, ainda, é no movimento de ação e reflexão sobre essa ação que conseguimos nos sentir como educadores. 
Também compreendemos que, depois de estar em uma zona de risco, não mais é possível retornar à zona de conforto, não conseguimos nos limitar a ela. Pensamos que a aprendizagem oportunizada neste trabalho está relacionada a esse movimento. Almejamos que esta caminhada possa colaborar com a caminhada de outrem, que inspire outros educadores. Assim, deixamos ao leitor um convite e também a vontade para refletir e promover, em diferentes ambientes de aprendizagem, uma Educação Financeira Crítica.

\section{Referências}

ALRO, Helle; SKOVSMOSE, Ole. Diálogo e aprendizagem em educação matemática. São Paulo: Autêntica, 2010.

ANDRÉ, Marli (org.). Formação de professores: a constituição de um campo de estudos. Porto Alegre, v, 33, n.3,p.174-181, set/dez, 2010.

ARAÚJO, Jussara de Loiola. Educação matemática crítica na formação de pós-graduandos em educação matemática. Belo Horizonte: Argvmentvm, 2007.

BAUMAN, Zygmunt. Globalização: as consequências humanas. Rio de Janeiro: Jorge Zahar Editor, 1999.

BITENCOURT, Karliúza Fonseca. Educação matemática por projetos na escola: prática pedagógica e formação de professores. Curitiba: Certa Editorial, 2010.

CHIARELLO, Ana Paula R. Educação Financeira Crítica: novos desafios na formação continuada de professores. 2014. Dissertação de mestrado em Educação- Universidade Comunitária da Região de Chapecó, 2014.

FREIRE, Paulo. Pedagogia da autonomia: saberes necessários à prática educativa. São Paulo: Paz e Terra, 1996.

PLS (Projeto de Lei do Senado) 171/2009. Disponível em www.senado.gov.br. Acesso em: 10 de mar. 2013.

MACHADO, Nilson José. Educação: projetos e valores. São Paulo: Escrituras Editora, 2000.

MORIN, Edgar. Introdução ao pensamento complexo. 2 ed. Lisboa: Instituto Piaget, 2001.

SKOVSMOSE, Ole. Educação matemática crítica: a questão da democracia. Campinas-SP: Papirus, 2001.

. Educação crítica: incerteza, matemática, responsabilidade. São Paulo: Cortez, 2007.

Desafios da reflexão: em educação matemática crítica. Campinas, Sp: Papirus, 2008.

SKOVSMOSE, Ole; PENTEADO, Mirian Godoy. Trabalho com projetos na educação matemática. 2008. Disponível em:

http://www.sbem.com.br/files/ix_enem/Comunicacao_Cientifica/Trabalhos/CC232384518 71T.doc. Acesso em: 10 de mai. 2013. 
SILVA, Everson M. Reflexão de Paulo Freire: uma contribuição para a formação continuada de professores. V Colóquio Internacional Paulo Freire. Recife. Set./2005.

VAILLANT, Denise. Iniciativas mundiales para mejorar la formacíon de professores. R. Bras. Est. Pedag., Brasília, v.1, 2001. 